\title{
Design and Strategy of Digital Exhibition Space for the Display of Archives Through the Comparison of Museums with the Newly Developed High Technological Application
}

\author{
Jaeho Ryu ${ }^{1}$, Minsuk Kim ${ }^{1}$, Yeonhong Min ${ }^{1}$, Minhee Jung ${ }^{1}$, Jungin Lee ${ }^{1}$, Sangyul \\ Lee $^{1}$ and Eunsang Cho ${ }^{1}$ \\ ${ }^{1}$ Seoul National University of Science and Technology \\ 232 Gongneung-ro, Nowon-gu, Seoul, Korea \\ \{jhryu, 14143310,f5d1, shai147, jeny0830,ruke93, 1600659\}@seoultech.ac.kr
}

\begin{abstract}
Museums are places for the exhibition of cultural, historical, and technical events for education of visitors of all ages and genders. Therefore, every museum has its own method to show the contents and events with the traditional or cutting-edge ways to effectively and efficiently carry the information to the viewers. Recently, the digitalization of archives has become common in many museums and the use of $3 D$ data has become one of the central issues of digital exhibition. In the present study, we investigated several museums with a relatively large scale of exhibition spaces and actively adopted the newly developed technologies in order to get useful guidelines and lessons for building the digital exhibition space design and strategy. Specially, we focused on several efficient digitally mediated technologies for the display of digital $3 D$ data of objects in the exhibition. The WebGL, augmented reality (AR), and pseudo-hologram technologies were investigated and suggested as effective strategies to display the $3 D$ digital contents in an exhibition space. During the development of these applications, the interaction between users (visitors) and digital contents of a display system was our main concern, as we aimed to create an interesting and immersive exhibition experience for the audience. The results of this paper provide helpful insights for designing and setting up a space program of a digital exhibition and displaying the contents with the newly developed high technological application.
\end{abstract}

Keywords: Digital Exhibition, Design and Strategy of Space Program, Digital 3D Data, WebGL, Augmented Reality, Pseudo-Hologram

\section{Introduction}

Museums are places for the exhibition of cultural, historical, and technical events for education of visitors of all ages and genders. Sometimes, the targets of the display are historically valuable objects or politically valuable archives. Overall, each museum has its own purpose of emphasizing certain aspects, such as art, history, science, nature, and so on. When planning the space of an exhibition, we have to consider the purpose of the museum and the exhibition to effectively carry the information about the displayed items to the audience. Therefore, this paper seeks to find a proper design and strategy of digital exhibition using digital 3D data to provide the guidelines for the new concept of display design.

Real objects of archives have some disadvantageous aspects of exhibition in public space, because, sometimes, it is difficult to openly exhibit items that are historically and politically important. Therefore, for security and safety reasons, substitutes of original objects in an exhibition can be displayed in the digital format of 3D data of the objects preserved in national archives. Furthermore, another advantage of using the digital exhibition system is the easy application of the digital format. For these reasons, many 
museums have recently scanned the archives they preserve and made backup of the database for future applications. One of the targets of the present study is to find a solution for a more effective and efficient management of these databases.

Another topic of this research is how we can apply the digital 3D data format, which has been produced for several purposes using various methods, for exhibition purposes. As the accumulated original digital formats are not suitable for digital display purposes, a proper workflow to use the original digital 3D data for an exhibition should be established. The recently developed technologies, which are useful in terms of delivering exciting exhibition services for the public, can realize the display system and software framework. In this study, the target audience of an exhibition is not specified to a certain age and gender. Therefore, the exhibition strategy proposed in the present study will be the overall design of an exhibition plan, including both the real and the cyber world.

\subsection{Design and Strategy of Digital Exhibition}

Recently, museums have changed their exhibition strategies according to the development of preserves and display technologies of their archives. One of the traditional methods is to show the original archives in their real form or as replications in a physical space. This exhibition design and strategy requires physical space and several equipment devices so that to preserve the original archives and to protect them from ultraviolet rays and humidity which are the main causes of degeneration. Furthermore, the real exhibition strategy is both time- and money-consuming method. Obviously, it has the big advantage of using original archives for exhibition, as compared to other methods. The priceless value of the original archives is one of the great merits of the exhibition contents for its viewers. However, the real exhibition strategy limits the space and the time of display. The previously mentioned prerequisites are also necessary for the physical and real exhibition.

The increasing possibilities to virtually experience the digital data of a 3D object and the accumulated scanning data of the archives are changing the current exhibition strategy. The possibility to experience the virtual world makes the public get used to seeing digital data. Also, the detailed and accurate scanning data produce a more realistic image of the objects for the viewers. Therefore, except for the originality of the displayed objects, a digital exhibition has many merits, such as easy access, extension of archives by digital duplication, scalable display of archives, and adding interaction. In this context, it can be said that nowadays we are witnessing a turning-point period from the analogue method to the digital one in the exhibition field. When using the digital exhibition method, we have to use the proper design and strategy of exhibition to give the effective experience of museum to audiences.

\subsection{Display of Digital 3D Data of Object}

When considering organizing a digital exhibition, computer graphics and data format of the 3D data are essential factors for the exhibition strategy. The representation of real objects using computer graphics is not standardized to one digital format, as every digital format has its merits and demerits. Therefore, the diverse formats of 3D data of real objects are among central concerns in the preparation of a digital exhibition.

Usually, the detailed accumulated digital 3D data will be the scanning data of real objects. Sometimes, the acquisition of UV map is automated process from the scanning data. Another alternative is hand-made processes. In addition, the data format is not determined to one possibility; therefore, appropriate conversion methods of file formats or transforming them for actual applications need be determined. In general, the 3D data format can hardly be converted to another format without losing some information. Even though the missing data are not the essential part of the 3D data itself, still, minimizing the amount of the mismatch between the original version and the converted results of 3D 
data will be an urgent goal of this project. Overall, *.obj format is the most common 3D data file format in computer graphics to be converted from and to other file formats. For that reasons, in the present study, the *.obj file format is used as the common data format.

\subsection{Digitally Mediated Technology of Display in Exhibition}

Recent advances in the presentation technologies of the digital 3D data using devices are quite impressive from the perspective of experience. First, the high resolution of flat display devices is the most important part of the composing a virtual space in the digital world. Without a high-quality display image, the viewers' experience cannot be genuinely immersive. Second, there are many applications for the interaction between humans and computers using various sensors. In recent years, interface technologies have considerably progressed, thereby reduce the gap between humans and computers. Actively adapting the latest interface technologies is the one of the aims of the present research.

In this study, we used the recently developed technologies in the area of computer graphics, including WebGL, AR, and pseudo-hologram. These technologies were selected through the investigation of several museums, as they are particularly useful and powerful in terms of displaying the digital data for the public with entertaining factors and user interaction. However, in order to realize an exhibition system and appropriate software, we need to establish a specific strategy for each museum-a strategy that would maximize the functionality of the used technology. Also, the method of browsing and navigation in digital contents will require different solutions and means within each of the technologies.

\section{Exhibition Design and Strategy in Museums}

Every museum has its own specific purpose of displaying the preserves and its own specific characteristics. As mentioned above, the best and most used method is displaying the original archives in a real space. However, the purposes of museums and the characteristics of their preserves vary, although there are common factors of design and strategy in an exhibition from the general aspect of viewing the preserves. This is the one of the reasons why digital devices for display have been applied in almost all kinds of museums. In this chapter, we investigate several museums and figure out the general exhibition strategy. Furthermore, based on our analysis of some museums that adopted special methods to enhance viewers' experience with more entertainment devices, we suggest a new exhibition method.

In order to figure out the common display strategy of famous world museums, we have gathered the digitally mediated display examples of the Smithsonian museum in Washington D.C. The Smithsonian is the world leader in the exhibition field and specializes in natural science, the space and air planes, traditional culture, among other domains. Furthermore, the high quality of its exhibition contents and the well-designed exhibition program are additional aspects to select this museum for our investigation. The other museum of our choice is Jeju Aerospace Museum in South Korea. This museum was selected because the contents of its exhibition are similar to those of the National Air and Space Museum in Washington D.C. In Jeju Aerospace Museum, we can find the newly adopted technologies with more interesting and interactive methods to the tour course. Jeju Aerospace Museum is equipped with relatively new technologies compared to the Smithsonian museum because it was completed in recent years.

\subsection{General Strategy of Digital Exhibition}

Both museums have several common strategies of exhibition using digital display technology. The most common method is showing the information on flat display screens. Sometimes, it can be a small monitor between the panels. Sometimes, it can be large LED display devices or projection screens on the walls. At all events, the technical progress in 
the device thickness and large display screen is helpful to design many application of flat display in exhibition.
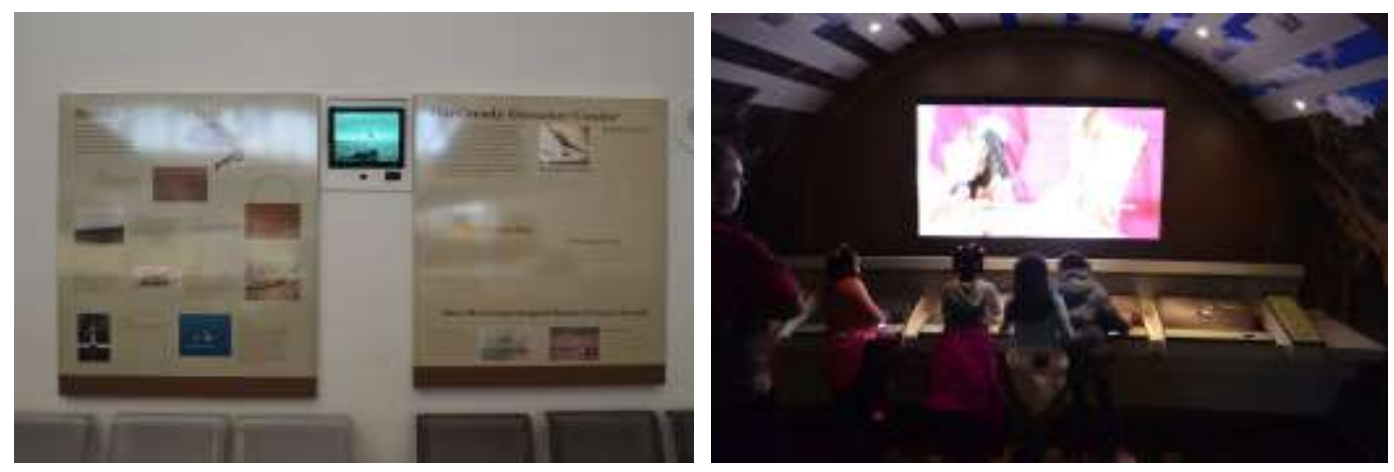

Figure 1. A Flat Screen Display for Providing Additional Information of a Panel

Figure 1 shows that the extensive use of flat screen displays in the exhibition process in the Smithsonian Museum. Among digitally mediated technologies, the flat screen display is a most useful and relatively inexpensive device. Therefore, displays of this type are extensively used in the museum. In some cases, it can be a temporary mini theatre to show the story of exhibition contents during the guided tour. The audience can stop there to get further knowledge about the exhibition contents not only from the original preserves, but also from an additional digital display screen.
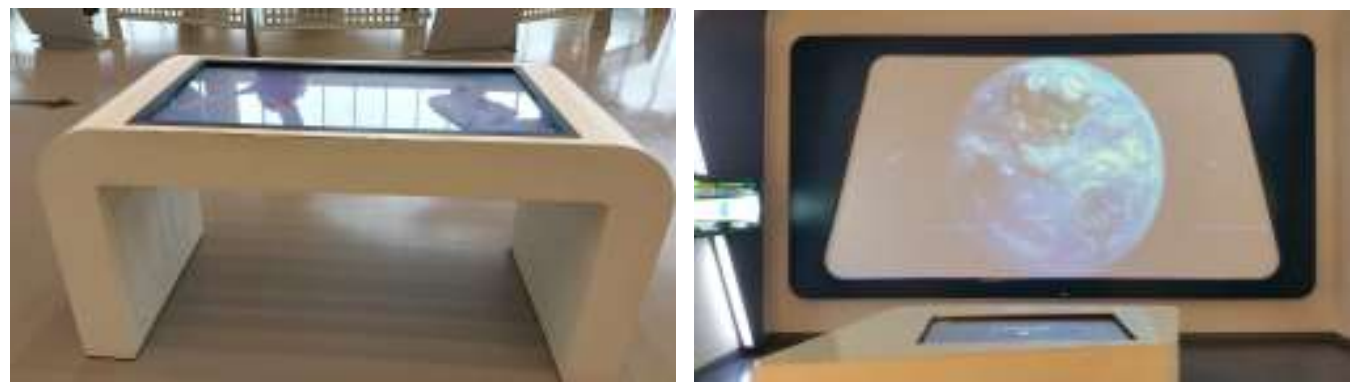

Figure 2. Flat Screen Display to Convey Additional Information

In Jeju Aerospace Museum, we can also find many cases of using flat screen displays. Figure 2 shows the workbench display style and the combination of wall and workbench display style during the course. In addition to this specific example, we can find numerous other instances of use of X in Jeju Aerospace Museum.

\subsection{Special Digital Display Technologies for Audience}

In addition to using flat screen displays as the most common method in the museum exhibition strategy, there are other methods for the display of digital information using various display technologies. In computer graphics and virtual reality, there has been much progress in the development of new display devices. These display devices can provide a more interesting experience to the viewers, as compared to the traditional flat screen display. The various display screen shapes are usually accompanied with various interfaces that provide a high sense of immersion and enable for a direct manipulation of a digital object in the virtual space. 

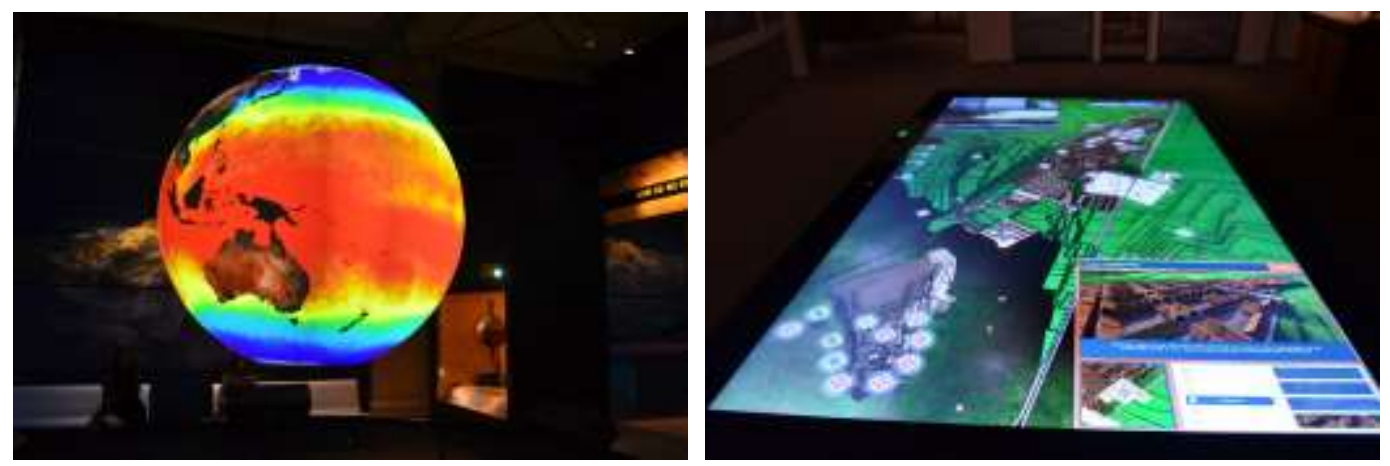

\section{Figure 3. A Sphere-shape Display System and an Interactive Workbench- Style Application of a Culture Site for an Immersive User Experience}

Figure 3 shows the special shape of digital information displaying device such as the sphere shape display system which is projected by four projectors and the workbench style of application of bird-eye view of culturally historic site. These devices will help audience to understand the exhibition better and have the high user experience about the digital display of contents. The workbench style display system is used a lot in the other places and cases which can provide the abundant interaction and entertaining factors for the audience. Usually the workbench style display is composed of touch screen for the natural and easy controlling of contents of application. Also this is the extended version of the mobile pad and tablet device which are quite familiar to people these days.

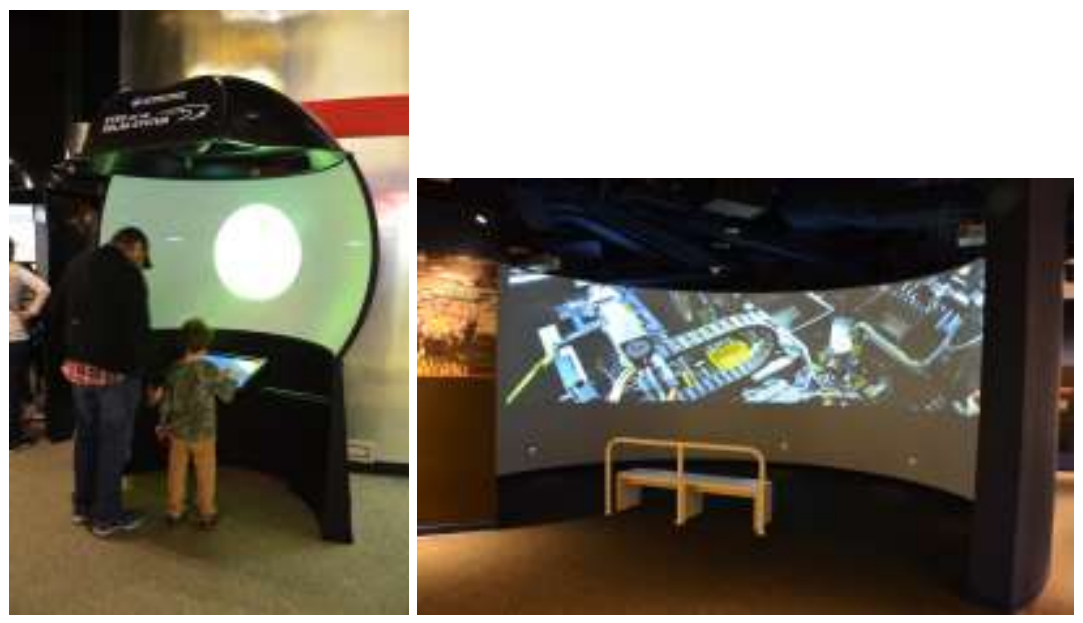
Figure 4. An Immersive Semi-sphere and a Curved Screen of the VR Display
System for an Immersive User Experience of Exhibition Contents

Figure 4 shows another special type of digital presentation devices that provide a highquality immersion experience, including such a semi-sphere screen system, a curved multi-projection display system, and so on. However, these devices are not the basic style of digital presentation, the attempt of application of this new style display system is significant and useful in terms of providing high-quality user experience for the audience. Sometimes, museums are equipped with a big size movie theatre, such 3D IMAX, 4D theatre, and so on. These theatres can provide a special user experience for the audience through the high resolution, stereoscopic image of the movie, and multi-sensory effects. 

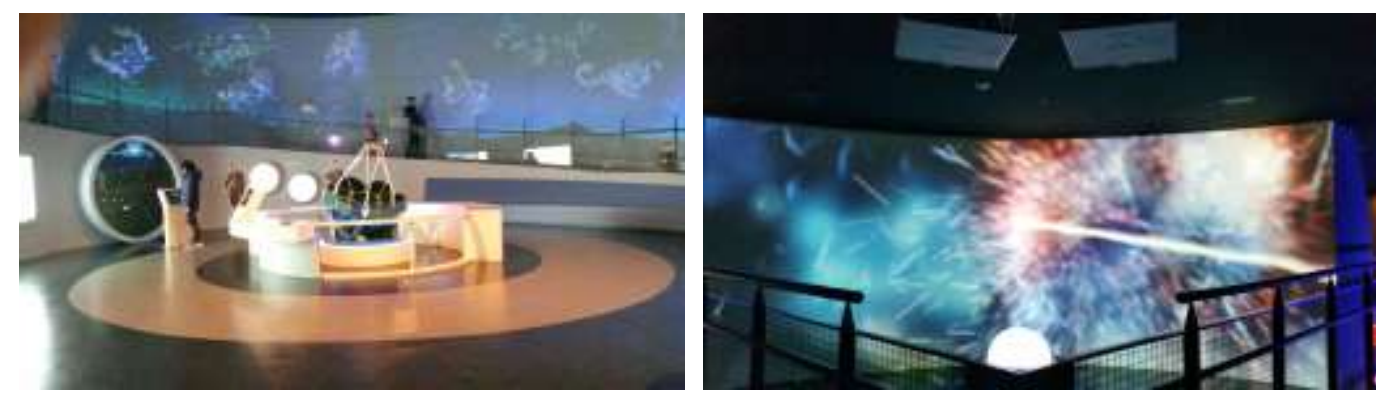

Figure 5. A Curved Wall Screen Display and a Small Curved Screen Space

The projection screen display is not limited on the planed screen, but can be applied to a space element, such as the wall and the floor of a room. The variability of screen shapes and places is the one of the biggest merits of a projection display system when one is considering designing an exhibition space with digital presentation. Figure 5 shows a good example of using a projection display application in a space on the wall and the floor. Thus, when using a large scale projection display system in the exhibition space, it is difficult to distinguish a space design element and a digitally mediated display technology.
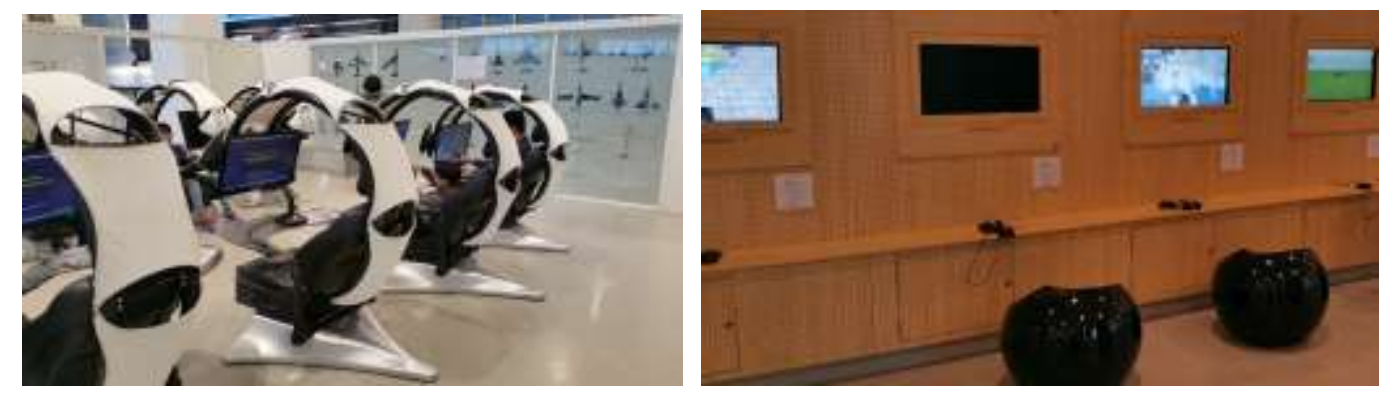

Figure 6. A Flight Simulator and a Game Style Console Desk Area

In Jeju Aerospace Museum, there is a special exhibition area for kids where they can experience the exhibition contents with a special simulator and game style devices. Figure 6 shows a flight simulator and a game console desk for the audience. The purpose of this exhibition strategy is to provide interactive enjoyment and a more impressive experience for the viewers. Compared with a simple flat screen display or just watching a projection screen display, the entertainment and interaction ensured by exhibition devices facilitate the delivery of intentional information to the audience. This is one of our valuable results in terms of building a new strategy of digitally mediated display technologies in an exhibition. When planning an exhibition strategy with the newly developed technologies, there are more possibilities to integrate these factors into museum exhibitions.

\subsection{The Other Strategies of Museums for Audience}

Conventional flat screen theatres are located in every museum at regular distance intervals during the exhibition course. The function of these theatres is to provide resting time and place with seating chairs and isolated spaces. This space can play a role of a presentation room and a resting place, because the space still provides the information about the exhibition. In an arts museum, there will conventionally be a sofa for the appreciation of paintings or sculptures in front of them. This sofa is a consideration of human physical limitations in terms of walking and standing capacities. This is one of interesting findings of the characteristics of space planning from the investigation for several world-famous museums. 

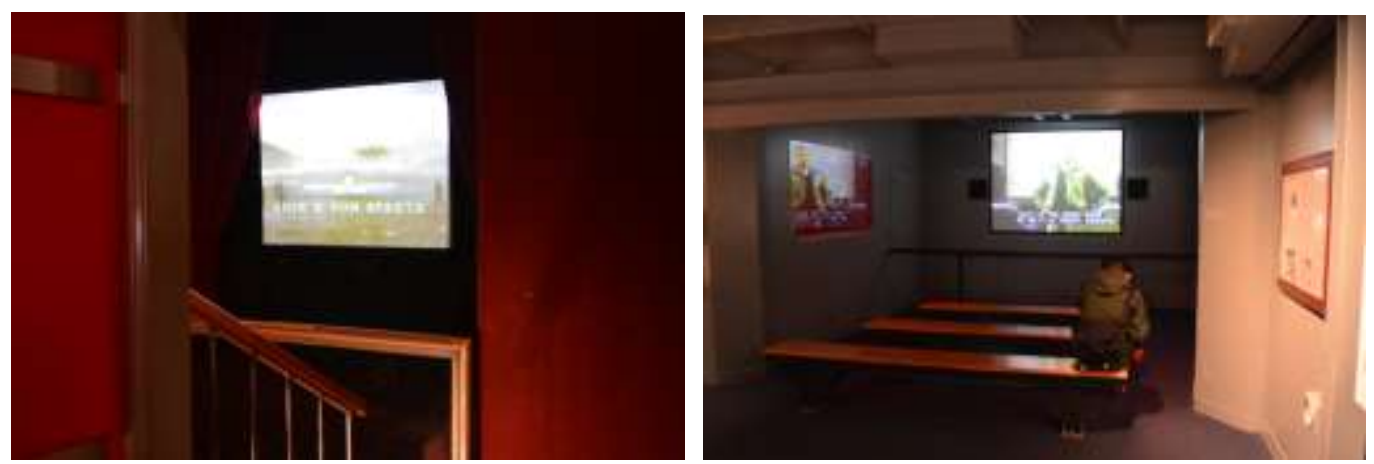

Figure 7. A Pocket Theatre During Tour Course

Throughout the present investigation of museums, we observed a special effort to build extra display environments to provide the information with the impression for the audience, such as a sphere display, a curved screen, a wall screen, and a hemi-sphere display. The purpose of all these devices is to enhance the experience of exhibition. The museum staff tried to achieve effective exhibition results using recently developed technologies. The essential reason of adopting these various technologies is the user exhibition experience. To conclude, the augmented reality (AR), virtual reality (VR), and WebGL technologies have a high potential of bringing a higher-quality user experience and customized service for the audience.

\section{Characteristics of Digitally Mediated Technologies}

\subsection{Three Digitally Mediated Technologies for Exhibition}

In what follows, we analyze three digitally mediated exhibition technologies: WebGL, AR, and pseudo-hologram. These technologies were selected due to the ease of their application and their accessibility to the public. The WebGL technology is based on the Internet, which makes it the most friendly environment for the public to access. Also, common Internet browsers, such as Chrome, can be used for the viewer of these contents, which is the biggest merit of building this system. Recently, the AR technology has spread out to the public in various fields, which makes it entertaining and interesting to use in museum applications. Also, everyday portable smart devices are one of the positive aspects of using this technology. Pseudo-hologram is another interesting technology which deceives the viewer's eye with the reflected four-sided animated display. Pseudohologram can provide user interaction without a direct manipulation of sensors. However, although pseudo-hologram differs from real hologram, it still offers high-quality user exhibition experience. In section $\mathrm{X}$, we will further discuss the pseudo-hologram technology in terms of its advantages (such as interactive effects and low cost of construction).

Table 1. Characteristics of Selected Technologies

\begin{tabular}{|c|c|c|c|}
\hline & WebGL & $\begin{array}{l}\text { AR(A ugmented } \\
\text { Reality) }\end{array}$ & Pseudo-hologram \\
\hline Accessibility & $\begin{array}{l}\text { Easy to access } \\
\text { (by internet) }\end{array}$ & $\begin{array}{l}\text { Easy to access } \\
\text { (by internet, smart } \\
\text { phone or pad) }\end{array}$ & $\begin{array}{l}\text { Little hard to access } \\
\text { (physical space) }\end{array}$ \\
\hline Entertainment & High & High & Middle high \\
\hline Interaction & High & High & High \\
\hline Containing & Many items & Limited items & Limited items \\
\hline
\end{tabular}




\begin{tabular}{|l|l|l|l|}
\hline $\begin{array}{l}\text { number of } \\
\text { contents }\end{array}$ & $\begin{array}{l}\text { Relatively easy to } \\
\text { maintain (server and } \\
\text { client computer) }\end{array}$ & $\begin{array}{l}\text { Relatively hard to } \\
\text { maintain the system } \\
\text { (rental portable smart } \\
\text { device) }\end{array}$ & $\begin{array}{l}\text { Hard to maintain } \\
\text { the system } \\
\text { (complex hardware } \\
\text { composition) }\end{array}$ \\
\hline
\end{tabular}

Table 2. The Proposed Digitally Mediated Technology for the Exhibition of 3D Archives to the Audience

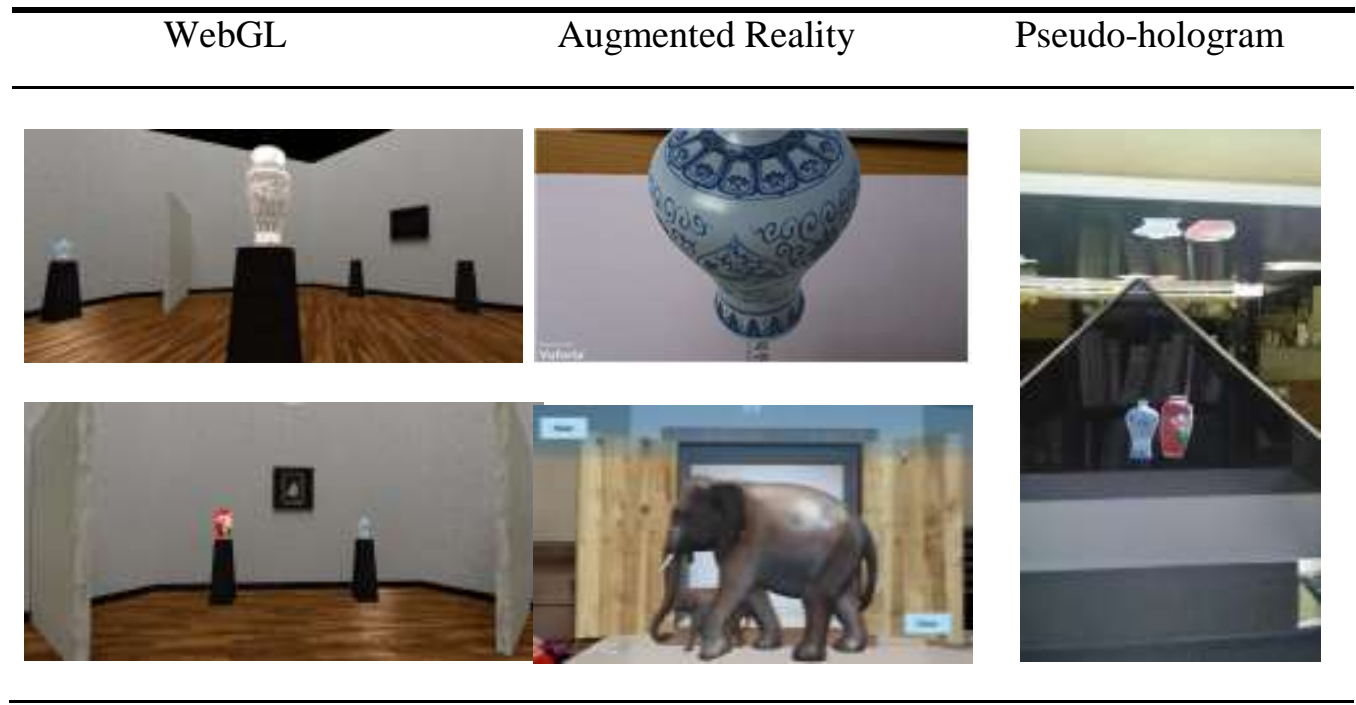

\subsection{WebGL}

Recently, WebGL (Web Graphics Library) has become a popular technology to express the cyber 3D world in the World Wide Web (WWW) without an additional installation of plug-ins to the common Internet browser. The computer graphics library is composed of the JavaScript API to render the interactive 3D world in the Web. The loading of the digital 3D data and texture map is the essential part of realizing the threedimensional space in the Web for an exhibition. A special function of this system for the user who navigates the cyber museum space with a browser is the information pop-up window that conveys additional information about the archive. The transition method from one cyber space to another one is necessary to realize the multiple exhibition space design according to the category of archives.

The realistic feeling of the cyber world is the essential part of realizing the 3D world in the Web to enhance the usefulness of a digital exhibition of an archive. In this study, we pursued two track ways: the texture-baking technology and the real-time rendering programming using JavaScript APIs. The texture-baking technology is a common method to save the rendering time of a computer even though the full real-time rendering is possible. The pre-calculated and baked lighting effect on the texture map is helpful for rendering of a scene when the main light is not changed in position and intensity. Therefore, we merged both skills of baking-texture and real-time rendering scripting to improve the realistic rendering image quality of a cyber museum which is based on the Web. This is a quite helpful solution in the case of limited computer power and client computer resources of cyber museum visitors.

\subsection{AR (Augmented Reality)}

The AR technology is a powerful application tool for the exhibition of the 3D data of original archives with the amusing interaction. The mobile device will be used to display 
the registered virtual 3D object on the screen of portable smart devices with various events and animations. In addition, the easy distribution of apps through the mobile application market is one of the advantages of using this technology for the un-specified target users in the exhibition area. User interface of the AR application in a mobile device is another factor of high-quality user experience to satisfy the exhibition purpose. The recent game-engine editor and the AR library of Vuforia SDK are used to realize the proposed display system. The customized user experience is the one of the merits of using this technology for the exhibition process. However, the limited audience who can enjoy this service in the exhibition spot is a disadvantage of applying this technology, because the number of rentable devices is small which have the best performance.

Creating a tour scenario is one of the key contents of the AR application for the digital exhibition using 3D model data. Simple showing of a 3D object image on the screen is not an interesting skill anymore. In our application, the user can record what they found during the tour course to be evaluated for the faithful appreciation. Also, users can open specific archives on a screen separately in order to magnify, rotate, and pop-up additional information in the window.

\subsection{Pseudo-Hologram}

Pseudo-hologram differs from the real hologram technology. This technology relies on human visual deception of a reflected image of a four-sided display. In this research, the pyramid style pseudo-hologram was adapted for the exhibition of 3D data in the digital format. In this system, the interaction factor will be essential, because the action and reaction between the human and the digitally display image in the pyramid screen will be the activator of a high-quality user experience. One of the important factors of this system is the amusing interaction of the audience with a pyramid-style pseudo-hologram. A camera, Leap motion sensor, and Kinect sensor are used to make a connection between the digital contents and the audience to provide an interesting interaction. The user can move, rotate, and change the model using a marker and a Leap motion sensor. Also, users can create, move, and delete the flare effect inside the virtual space through moving their hand position through a Kinect sensor. All of these aspects add entertaining and interesting aspects to the interaction of users to make the viewing experience more effective.

In terms of the space design for an exhibition area, the exhibition method using pseudo-hologram can be used in a relatively small space, as compared to a real archive display. Also, the registered 3D digital contents are not limited to the exhibition space, because we can register a sufficient amount of content, provided the computer resources allow for it. We can change the exhibited digital 3D archives by switching the markers.
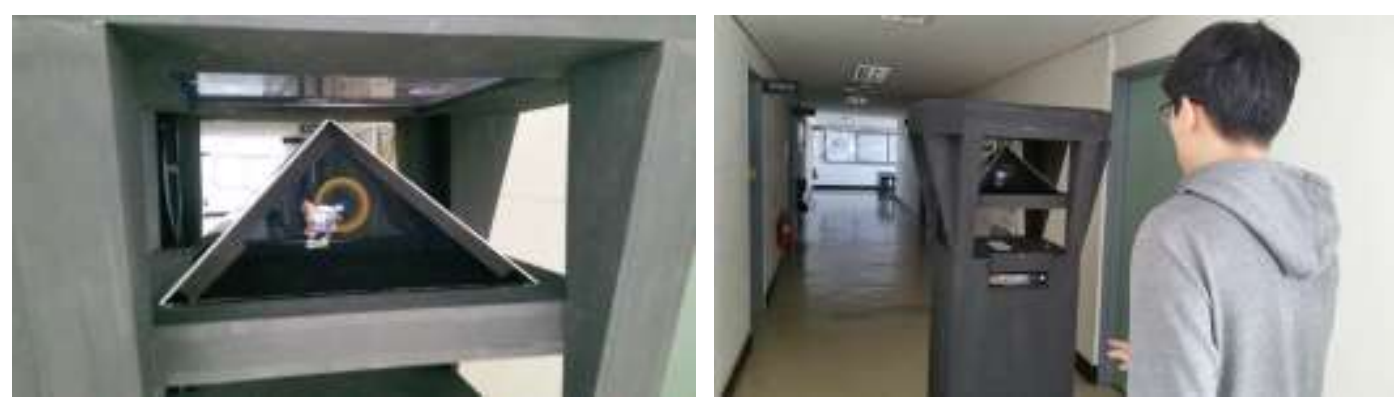

Figure 8. Interaction Using Various Sensors in Pseudo-hologram 


\subsection{Conversion of Data Format of a 3D Object for Exhibition}

The data conversion is an important issue of using digitally mediated technologies for the exhibition strategy, because it is natural that the accumulated 3D data usually exist in various file formats. As mentioned above, there are two main methods to produce the digital 3D data, namely, the 3D modeler creation and the 3D scanning. There are many 3D modeling tools that have their own original file formats. Sometimes, it is hard to communicate with each other because the data are not standard format. The main difference between the file formats created with the 3D modeler creation and the 3D scanning is whether it is polygon or point cloud data. In this study, we chose the *.obj as the common file format for all three digital exhibition technologies. This format will reduce the time and effort of museum staff, as they can share the produced digital 3D data and eliminate the unnecessary steps in the data conversion process.

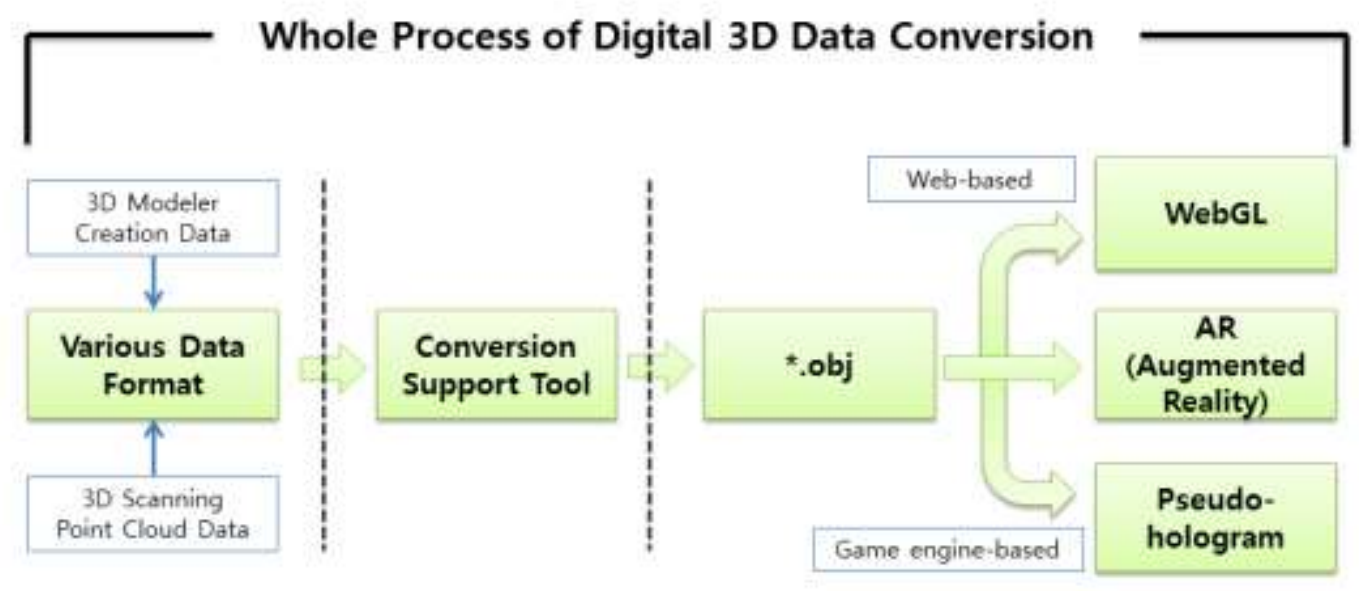

Figure 9. Digital Data Conversion Process

\section{User Experience of Display of Digital Data}

In creating an exhibition system using a digitally mediated technology, the user experience of this digital display is the crucial consideration point. Appropriate entertainment and information are necessary to satisfy the audience with an exciting viewing experience. In the WebGL application, the cyber space and the navigation strategy will be the first consideration for the display of a 3D object. The advantages of this application include its easy accessibility, navigation, enjoying the event, and interaction between the user and the created digital contents.

The AR is a promising technology for the display of archives in the several methods. The 2D and 3D markers can be used for the recognition of the position and direction of a virtual object representation. The AR can be installed in the mobile devices which are common these days, which make this technology so popular among younger generation. Adding the virtual space and objects to the real space will be a new methodology for creating a new concept beyond the physical time and space. The audience can interact with the digital contents, which will make their experience more vivid.

Pseudo-hologram is an interesting technology that uses visual deception. The proposed system will display the digital contents with various interactions when the user feels the realistic objects inside of the half mirror screen of the pyramid face. The contactless interaction using a sensor device will give the freedom and joy to the audience which will produce a high-quality user experience. The specific target audience of this system is younger viewers. 


\section{Conclusion}

In this study, seeking to establish some guidelines to set up the design and strategy of a digital exhibition, we investigated several museums that actively adopted new developed technologies. Our main finding is that there is a new current trend in the museum exhibition domain to provide more interaction and entertainment factors to enhance the exhibition results. Based on this findings, we propose using three types of digitally mediated technologies for the exhibition of digital archives of 3D objects: WebGL, AR, and pseudo-hologram. These technologies are relatively easy to be constructed and adopted in an exhibition space. WebGL, AR and pseudo-hologram can be integrated with interesting and entertaining tour scenarios and contents to provide an enhanced user experience during the appreciation of digital archives. More interaction between the audience and digital archives is the intended aim of our proposal. Also, one of the results of this research is the conversion workflow of the 3D data format to be used in the proposed digital display technologies.

Our results on the methods of digital exhibition using three digitally mediated technologies will help promote and enhance digital archives exhibition designs and strategies. Our results also suggest economically and efficiently useful insights for the provision of educational services for the younger museum audience.

\section{Acknowledgments}

This paper is a revised and expanded version of a paper entitled "Exhibition Strategy of Digital 3D Data of Object in Archives using Digitally Mediated Technologies for High User Experience" presented at GST2016, Jeju, December 2016.

This research was supported by "Archive Preservation Technology R\&D Program" funded by the National Archives of Korea (NAK).

\section{References}

[1] I. Khan and S. S. Hong, "A proposed image stitching method for web-based panoramic virtual reality for Hoseo Cyber Museum", Journal of the Korea Academia-Industrial cooperation Society, Vol. 14, no. 2, (2013), pp.893-898.

[2] J. Kim, "A study on exhibition as entertainment in recent museum", The Korea Academia-Industrial cooperation Society Semiannual, Vol. 29, Issues 3 (2010), pp. 777-780.

[3] J. Ryu and M. Kim, "A Study on the display design of Cyber Museum using WebGL in the internet", Autumn Symposium of Architectural Institute of Korea, Vol. 36, no. 2 (2016), pp. 1114-1115.

[4] J. Ryu, Y. Min and M. Jung, "The Characteristic of Exhibition Space with Augmented Reality Technology in View of Virtuality", Autumn Symposium of Architectural Institute of Korea, Vol. 36, no. 2 (2016) pp. 1240-1241.

[5] J. Ryu, and I. Jung, "A Study on the Design of Stage and Exhibition Space by Using Pseudo-hologram", Autumn Symposium of Architectural Institute of Korea, Vol. 36, no. 2 (2016), pp. 114-1115.

[6] M. Hirose and Tomohiro Tanikawa, "Overview of the Digital Museum Project", VRCAI '10 Proceedings of the 9th ACM SIGGRAPH Conference on Virtual-Reality Continuum and its Applications in Industry, Seoul, South Korea (2010), December 12-13.

[7] M. Ha, Y. J. Lee and S. H. Park, "A study on exhibition model and customized service according to type of audience in virtual museum", Design Convergence Study, Vol. 15, no. 6, (2016), pp. 145-160.

[8] M. Kwon and J. Kim, "Using Augmented Reality Programs For Children Proposed Research Model", Journal of the Korea Academia-Industrial cooperation Society, Vol. 13, no. 2, (2012), pp.866-871.

[9] R. T. Azuma, "A Survey of Augmented Reality", Presence: Teleoperators and Virtual Environments, Vol. 6, no. 4, (1997), pp.355-385

[10] T. Narumi, T. Kasai, T. Honda, K. Aoki, T. Tanikawa and M. Hirose, "Digital Railway Museum: An Approach to Introduction of Digital Exhibition Systems at the Railway Museum", Lecture Notes in Computer Science, Vol. 8010, (2013), pp.238-247.

[11] J. Ryu, M. Kim, Y. Min, M. Jung, J. Lee, S. Lee, E. Cho and W. Joo, "Exhibition Strategy of Digital 3D Data of Object in Archives using Digitally Mediated Technologies for High User Experience", Proceeding of the 3rd International Conference Proceedings of GST2016, Jeju Island, Korea, (2016) December 21-23.

[12] http://www.web3d.org/, Web3D Consortium

[13] https://threejs.org/, JavaScript 3D Library 
International Journal of $u-$ and e- Service, Science and Technology

Vol.10, No.8 (2017)

[14] https://www.khronos.org/webgl, WebGL, Khronos Group

[15] https://www.blender.org/manual/render/blender_render/bake.html/, Render Baking 